\title{
الالكسيثيميا وعلاقتها بالتدين لاى طلبة الجامعة
}

*فراس عبد الخالق منديل طالب دكتوراه

Faras99@yahoo.com

Tel. 07831324335
أ.م. د. باقر طالبي دارابي

\section{b.t.darabi@gmail.com}

989360852420 Tel.

جامعة الاديان والمذاهب/ قم المقدسة / ايران

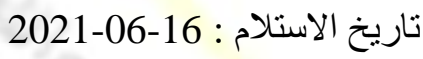
2021-06-22: تاريخ القبول

الخلاصة

اقتصر البحث على عينة مؤلفة من (400) طالب وطالبة من طلبة جامعتي القادسية والكوفة لكلا الجنسين (ذكور، وإناث)، و التخصص (العلمي، و الإنساني) للعام الدراسي (2019-2020) وقد تم تطبيق المقاييس عليهم الكترونباً بسبب جائحة كورونا، ولتحقيق أهداف البحث الحالي تبنى الباحث مقياس تورنتو للاكسيثيميا (Toronto Alexithymia Scale: TAS-20) لباجبي وزملائه ( Bagby parker \& Taylor, 1994 يحتوي هذا المقياس على (20) فقرة في ثلاث مجالات : (صعوبة تحديد المشاعر، صعوبة وصف المشاعر،التوجه الخارجي في التفكير). اما مقياس التدين فقد اعد الباحث المقياس في ضوء المنظور الاسلامي بصيغة أولية مؤلفاً من (26) فقرة ، وصيغت الفقرات على شكل عبار ات تقريرية ، لكل موقف خمسة بدائل هي (أو افق تماماً، أو افق بدرجة كبيرة ، أو افق بدرجة متوسطة ، أوافق بدرجة قليلة، لا أوافق ابدا). ، ويعطي البديل الأول الدرجة (5) و البديل الثاني الدرجة (4) و البديل الثالث الدرجة (3) والبديل الرابع الدرجة (2) و البديل الخامس الدرجة (1) واظهرت النتائج الاتي تتمتع العينة بمسنوى منوسط من الالكسيثيميا، وان منوسط درجات أفراد العينة كان غير دال إحصائية. تتمتع العينة بمسنوى عالي من التدين، وان منوسط درجات أفراد العينة على مقياس التدين كان دال إحصائية. وجود علاقة ارتباطيه عكسية دالة بين الالكسيثيميا و التدين لدى طلبة الجامعة. الكلمات المفتاحية : الالكسيثيميا ، العلاقة بالتدين، طلبة الجامعة. 


\title{
Alexithymia and its Relationship to Religiosity among University Students
}

\author{
A.M.D. Baqir Talbi Darabi \\ Firas Abdul Khaleq Mindeel
}

Receipt date 2021-06-16

Date of acceptance: 2021-06-22

Abstract

The research was limited to a sample of (400) male and female students from the University of Qadisiyah and Kufa for both sexes (males and females), and specialization (scientific and humanitarian) for the academic year (2019-2020). The standards were applied to them electronically due to the Corona pandemic, and to achieve the research objectives The current researcher adopted the Toronto Alexithymia Scale: TAS-20 for Bagby and his colleagues (Bagby parker \& Taylor, 1994). This scale contains (20) items in three areas: (difficulty identifying feelings, difficulty describing feelings, external orientation in thinking ). As for the scale of religiosity, the researcher prepared the scale in light of the Islamic perspective in a preliminary form consisting of (26) paragraphs, and the paragraphs were drafted in the form of reportable statements. For each position there are five alternatives: (completely agree, agree to a large degree, agree with a medium degree, agree with a little degree, disagree. Start). The first alternative gives grade (5), the second alternative is grade (4), the third alternative is grade (3), the fourth alternative is grade (2) and the fifth alternative gives grade (1), and the following results showed

The sample has an average level of alexithymia, and the average scores of the sample members were statistically insignifican 'The sample has a high level of religiosity, and the average scores of the sample members on the sc of religiosity were statistically significant .The existence of an inverse correlation between alexithymia and religiosity among university students.

Keywords: Alexithymia, Relationship to Religiosity, University Students 
قد شغل في السنوات الآخيرة عجز بعض الأفراد عن التعبير عن مشاعرهم الداخلية الناجم عن تدني وعيهم بوجودها وضيق افقهم في التصور والتخيل العديد من الباحثين والعاملين في المجال الأكلينيكي لما يتركه ذلك العجز من تأثيراً كبير على السلوك الديني ، و الاجتماعي والاخلاقي لهؤلاء الأفراد (40 : Luminet, et.al, 2006 ) ، وبالتالي يتصفون بصفات وجدانية ومعرفية لشخصية تفتقر إلى الوعي بالانفعالات ، و عدم القدرة على تحديد تلك الانفعالات و المشاعر و وصفها و التعبير عنها لفظياً لأففهح أو للآخرين ، اضافة إلى صعوبة التمييز بين الانفعالات و الأحاسيس الجسدية الناتجة عن الاستثارة ، (Gilbert et al ., 2014:2) ، وهذا ما أطلق عليه فيما بعد بالاككيثميا (Alexithymia) التي وصفها (جولمان ،1995) على وجه الدقة بنقص المهارة الأساسية للذكاء العاطفي المتمثلة بالوعي بالذات ، ومعرفة مشاعرنا عندما تزعجنا انفعالاتـا الداخلية (جولمان ، 1995: 78 ) ). ومما لا شك فيه أن التذين هو القاعدة الوحيدة التي يجب أن تبنى عليها كل جوانب الحياة ، ذلك لأن صلة الإنسان بخالقه عامل حاسم في تحقيق توافقه النفسي و الاجتماعي مما يؤدي به إلى تتظيم شؤون حياته و تفاعلاته الاجتماعية (القعيب، 2003: 254) ، اذ ان التدين له دور حيوي في جميع المواقف التي يمر بها الإنسان في حياته بالإضافة لتأثيره البالغ في مختلف جوانب النفس الإنسانية بما يشمله من توجيهات وتعاليم لصالح الفرد وضمان عيشه بأمن و استقرار وطمأنينة وعليه تتحقق معايير الحياة النفسية السوية التي تعد المجال الرئيسي لعلم النفس (السويدي، 1989: 112). هذا ما أكدته نتائج دراسة (بركات، 2006) والتي هدفت إلى التعرف على تأثير الاتجاه نحو الالتزام الديني في التكيف النفسي و الاجتماعي عند طلبة الجامعة ، والتي أظهرت وجود تأثير جوهري لاتجاه الطلبة نحو الالتزام الديني في مستوى تكيفهم النفسي و الاجتماعي و لصالح ذو التوجه الديني المرتفع ، وهذا ما أكدته نتائج دراسة(عمامرة، 2018 ) التي توصلت إلى وجود علاقة ارتباطية موجبة دالة إحصائياً بين التذين و التوافق النفسي لدى طلبة الجامعة . بناء على ما تم ذكره آنفاً يمكن للباحث تحديد مشكلة بحثه بالإجابة عن تساؤل رئيس ، هو : ما العلاقة بين الأالكسيثيميا والتدين لاى طلبة الجامعة ؟ ثانياً. أهمية البحث: 
لا يتوقف تقدم الأمم على ما تملك من ثروات طبيعية كامنة في جوف أرضها فقط ، و انما يتوقف على الثروة البشرية الهتمثلة بأفرادها ، إذ ان الثروة البشرية لها اهمية كبيرة اذا ما قورنت بالثروة الطبيعية ، لان بدون الموارد البشرية لا يمكن كثف الموارد الطبيعية ، وتطويرها ، وجعلها مفيدة للإنسانية ، وعليه أن الأمم التي تهمل طاقاتها البشرية وتترك افرادها عرضة للمشكلات ، و الامراض و التخلف و الجهل و الفقر و الاضطرابات النفسية المختلفة ، فان ثرواتها ستكون متاحة للمستعمرين والنفعيين( حرش ،1982 : 27). و عليه أخذت تهتم الأمم على اختلاف درجات رقيها بالعنصر البشري و خاصة فئة الشباب لانهم مصدر امالها و استمرارها و الدافع الى تطورها الذي يمكن الاعتماد عليه في التتبؤ بمستقبلها (ابلحد ،1987: 27). و من جانب آخر تعد الانفعالات من أهم عوامل بناء العلاقات الاجتماعية بين الأفراد ، إذ من الصعب على الفرد التكيف نفياً و اجتماعياً دون علاقات مع الآخرين، إذ أن التواصل مع الآخرين و فهم مشاعرهم يسهم إلى حد كبير في تيسير عملية التفاعل الاجتماعي ، والقدرة على تتظيم الانفعالات الذاتية وضبطها كما أنها - أي الانفعالات - حلقة وصل بين المكون المعرفي و المكون السلوكي فهي تتظم السلوك الإنساني وتوجهه وتضبطه و تكبحه ، لذلك تزيد من تبصر الفرد بنفسه ( بني يونس ، 2009: 176). و الالكسثيميا تعد واحدة من الموضوعات الحديثة التي نالت أهتمام الدراسات النفسية لما تتطوي عليه من اضطرابات عاطفية و انفعالية و معرفية تظهر على شكل سلوكيات غير سوية في الحياة الاجتماعية ، وبالتالي تكون عائقاً إمام توافق الفرد النفسي و الاجتماعي و الأخلاقي و الديني (Agnieszka Zak-Golab et al,. 2008: 42) . و قد نالت دراسة التدين اهمية كبيرة إذ اهتمت به دراسات كثيرة سواء في المجمعات الإسلامية أو غير الإسلامية ، فقد توصلت أغلب نتائج الدراسات إلى وجود علاقة ارتباطية موجبة بين الاعتقاد و الالتزام الديني أو ما يعرف بالتدين وبين مظاهر الصحة النفسية و التوافق و السلام النفسي و غيره من المتغيرات النفسية و الاجتماعية الإيجابية ، وقد اتضحت أهمية التدين في كتابات رواد مدارس علم النفس على اختلافها فقد أشار (يونج ) إلى أن التدين يمكن أن يشفي أقوى مما تشفي نظريات( فرويد) و (أدلر)، كما يمكن أن يكون علاجاً أكثر فاعلية من العقاقير ، و يؤكد عالم النفس(مور) أن علة النفس في الحياة المعاصرة تكمن في الفجوة بين الدين و السلوك، كما يعد الفيلسوف وعالم النفس( ويليام جيمس ) الدين و ممارسة سلوك التدين أساس علاج أمراض القلق و التوتر و الخوف تلك الامراض التي تعد مصدراً لنصف امراض هذا العصر (بوعود، 2016: 198). 
كما ان للتربية الدينية أثراً مهماً في تكوين الضمير داخل النفس فإذا كانت التربية الدينية متزنة في توجيهاتها للفرد ، وجمعت بين الترغيب في الخير والثواب عليه وبين الترهيب من الثر و العقوبة عليه بحكمة فان الضمير ينمو نمواً سليماً في نفس الفرد ، و يؤثر إيجابياً في شخصيته ، وينعكس على علاقته بنفسه والآخرين ، فيقوى بذلك عنده الجانب الخلقي، ويبرز في تصرفاته ويكون دعامة قوية في نضج شخصيته وتماسكها (الصغير ، 2007: 168).

و لكون البحث الحالي يستهدف التعرف على العلاقة بين الالكسيثيميا والتدين لدى طلبة الجامعة فإن أهمية هذا البحث تظهر في الجوانب الآتية : n

1. أهمية دراسة عينة طلبة الجامعة هذا من جانب ، ومن جانب آخر المجال الذي سيفتحه البحث الحالي لمزيد من الدراسات المستقبلية التي قد تغطي أبعاد هذه المشكلة مما يسهل عملية تخفيف الالكسيثيميا عند الأفراد في سبيل زيادة سلوك التدين لديهح ·

2. تبرز أهمية هذا البحث من جهة أن نتائجه وتوصياته ستكونان عاملاً مساعداً للباحثين و المختصين في مجال الإرشاد

النفسي في وضع برامج إرشادية تساعد الطلبة بالتخفيف من الالكسيثيميا مما قد يؤدي الى تتمية سلوك التتين لديهح • 3. إن تعرف مستويات كل من الاككسيثيميا قد يعطينا تشخيصاً دقيقاً يسهل على المعالجين والمرشدين النفسيين في

المستقبل الإلمام بطبيعة المشكلة و معالجتها.

4. يُعد البحث الحالي أول محاولة علمية - بحسب علم الباحث- للتعرف على الآكسيثيميا وعلاقتها بالتدين لاى طلبة الجامعة ، بعد ان برزت ظاهرة الاككسيثيميا.

$$
\begin{aligned}
& \text { ثالثاً. أهداف البحث و فرضياته : } \\
& \text { 1. أهداف البحث : } \\
& \text { يستهدف البحث الحالي التعرف على : }
\end{aligned}
$$

(1) مستوى الالكسيثيميا لدى طلبة الجامعة .

(2) مستوى التدين لدى طلبة الجامعة .

(3) العلاقة الارتباطية بين الالكسيثيميا و التدين لاى طلبة الجامعة.

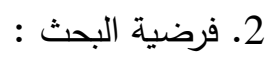


لا توجد علاقة إرتباطية دالة إحصائياً عند مستوى (0.05) بين الالكسيثيميا و التدين لدى طلبة الجامعة .

$$
\text { رابعاً. حدود البحث : n }
$$

$$
\text { تقتصر حدود البحث الحالي على الآتي: }
$$

(1) الحدود المكانية: العراق/ جامعتي الكوفة و القادسية.

(2) الحدود البشرية : طلبة الجامعة للدراسات الاولية الصباحية من الذكور و الإناث ، وكلا التخصصين العلمي و

$$
\text { · الإنساني }
$$

(3) الحدود الزمانية : العام الدراسي 2020-2021.

خامساً. تحديد المصطلحات:

: (1) (الاككسيثيميا (1)

$$
\text { عرفها كل من }
$$

-

" أضطر اب في بعض الوظائف المعرفية والوجدانية للفرد يظهر في تدني قدرته على استعمال الكلمات والتعبيرات

اللفظية المناسبة لوصف وتحديد مشاعره واحاسيسه الداخلية تجاه الآخرين ، و صعوبة في التمييز بينها وبين الأحاسيس البدنية المر افقة ، ونقص في التخيل ، ونمط التفكير ذو التوجه الخارجي (Sifneos, 1973: 257) . : ثوماس (Thomas et al, 1992) -

" قصور في القدرة على التلفظ بالمشاعر والتمييز بين الحالات الانفعالية المختلفة ، ومحدودية السعة التخيلية " ( Thomas et

. (al, 1992: 564

-

اعتمد الباحث تعريف - سيفنيوس (Sifneos, 1973) تعريفاً نظرياً ، وذلك لاعتماده مقياس تايلور و آخرون (Taylor) . لقياس الالكسيثيميا ، و الذي تم بناءه في ضوء هذا التعريف al., 1997 - - التعريف الاجرائي للالكسيثيميا : - 
الدرجة الكلية التي يحصل عليها المستجيب ( طالب الجامعة ) عن طريق إجابته على فقرات مقياس الالكسيثيما المُتبنى في • البحث الحالي : (2)

$$
\begin{aligned}
& \text { عرفه كل من : } \\
& \text { - }
\end{aligned}
$$

" التزام المسلم بعقيدة الايمان الصحيح (الايمان باله ، وملائكته ، و رسله، وكتبه، و باليوم الاخر ، و بالقدر خيره وشره )، وظهور ذلك على سلوكه ، وبممارسة ما امر الله به ، والانتهاء عن اتيان ما نهى عنه " (الصنيع ، 2002: 55). - - القحطاني و الطلافحة (2007):

" سلوك يمارسه الفرد من خلال تطبيقه لثرائع الدين المختلفة من عقائد و افعال و اقوال" (القحطاني و الطلافحة ، 2007:

$$
\text { - }
$$

" الطريقة أو المذهب الذي يسير عليه الفرد نظرياً وعلمياً ، وهو المنهج الذي يتبعه في حياته ، وفي علاقته مع غيره ، وفي عبادته لربه، وفي خضوعه الله تعالى" (الزحيلي ، 2008: 5) - التعريف النظري: بعد اطلاع الباحث على أدبيات التدين و التعاريف الانفة الذكر استتج تعريفاً نظرياً للتدين ، هو " سلوك يمارسه الفرد عن قناعة ، ناجم عن التزامه بعقيدة الايمان الصحيح وفعل ما امره الله به و الابتعاد عن اتيان ما نهى عنه "

- التعريف الإجرائي للتدين : الدرجة الكلية التي يحصل عليها المستجيب ( طالب الجامعة) عن طريق إجابته على فقرات مقياس التدين الذي تم بناؤه في البحث الحالي • اطار نظري ودراسات سابقة المحور الاول . الالكسيثيميا(Alexithymia): 
يرى بعض الباحثون أن سفنيوس(Sifneos,1973) أول من استخدم مصطلح (الالكسيثيميا) و التي إراد بها " لا يوجد كلمات تصف المشاعر" وهي مأخوذة من اللغة اليونانية (Alexithymia) المتكونة من ثلاث اجزاء ، هي (A) بمعنى لا يوجد ، و (Thymia) ، يعني كلمات (Thir et al, 2012: 2) (التي تعني المشاعر (Thi) ) وقد ظهر مفهوم (الالكسيثيميا) بشكل واضح ، و بوصفه مفهوماً نظرياً في مجال الثخصية خلال المؤتمر الاوربي الحادي عشر للبحوث السيكوسوماتية الذي عقد عام (1976) و أن المصطلح يتضمن: ( صعوبة في تحديد المشاعر و وصفها، و صعوبة في التمييز بين المشاعر و الاحاسيس الجسيمة ، و اضطراب الفاعلية الرمزية بوصفة مؤشراً لندرة النشاط التخيلي عند (Tahir et al, 2012:8) (الاخرين و التفكير الموجه للخارج) أسباب و عوامل ظهور الالكسيثيميا:

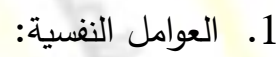

افترض (Dalbudak Evren,2010) ان تعرض الفرد في حياته المبكرة للصدمات التي تتضمن حرماناً عاطفياً او الاعتداء الجسدي و الجنسي قد يكون سبباً للألكسيثيميا في مرحلة المراهقة ، إذ يشعر الفرد ذو الاككيثيميا دائماً بالضعف و العجز في التواصل الاجتماعي ، و يفضل الانسحاب و يعاني من برود الحياة الزوجية و استخدام استراتيجيات سلبية للمواجهة مثل التجنب نتيجة لضعف المعرفة ، و سيادة التوتر و القلق و الصراع بين الزوجين وعدم الثعور بالراحة و صعوبة اتخاذ القرارات الحاسمة Dalbu المطلوب اخذها في الحياة و عدم و جود دعم نفسي، و وجود مستوى عدوانية مرتفع ، وقلة المرونة .(Evren,2010:1)

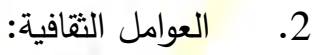

يرى جوكاما ( Joukamaa,2007 ) ان الاككسيثيا قد تكون صنيعة ثقافة محددة او عرق معين ، فالآكسيثيميا اكثر شيوعاً في الثقافات الغربية مما كانت عليه الثقافات الاسيوية ، كما وجد ارتباط بين الاككسيثيميا و التتشئة الريفية في عينة من السكان الفلنديين، اذ انهم يعيشون نمط الحياة التقليدية وهذا النمط لا يثجع الناس على التعبير عن عواطفهم ومشاعرهم بحرية ، و هذا يتضمن الرجال خاصة (33-32 : Joukamaa et al, 2007. 3. 
يؤكد (سيفينوس ونيمياه ،1973) ان الالكسيثيميا تنشأ عن وجود خلل وظيفي في بعض وظائف المخ العصبية المسؤولة عن معالجة و ادراك المشاعر، اذ ان النصف الايسر للمخ هو الميؤول عن العمليات اللفظية و التحليلية، بينما تتمثل مسؤولية نصف المخ الأيمن في القيام ببعض العمليات الكلية و الوصفية و عمليات الادراك و التعبير اللفظي عن المشاعر (كتغيرات الوجه ، أو بعض الحركات البدنية المعبرة عن المشاعر ( شعبان، 2015: 244).

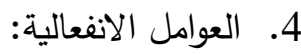

يُشير تايلر(Taylor, 2000) إلى أن الاككسيثيميا حالة شخصية مستقرة بسبب اختلال وظيفي في معالجة المعلومات المعرفية العاطفية و ضعف في خصائص الادراك المعرفي لمعالجة المشاعر، والافتقار الى التمثيل العقلي للعواطف ، و عدم القدرة على التظيم الذاتي و ندرة في المفردات اللغوية ونقص في الكلمات المستخدمة في التعبير عن العواطف تجاه الاخرين ويتضمن ضعفاً في التعبير عن المشاعر و زيادة نسبة القلق و الاكتئاب(Taylor, 2000:135).

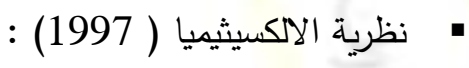

أشار (تايلر وباجبي وباركر ،1997) الى ان عدم القدرة على اظهار الوعي بالانفعالات الوعي بانفعالات الاخرين يكون بسبب الفشل المبكر في الحياة الذي يؤدي الى سوء تتظيم الوجدان وحدوث الامراض النفسية او البدنية، و ان هذا الفشل يكون نتيجة لتوقف أو نكوص إلى مستويات اكثر انخفاضاً من نمو الوجدان . و يرى (تايلر) ان الالكسيثيميا تتشأ عن خبرات سوء التكيف في الحياة التي عادة ما ترتبط بالتتشئة الوالدية الضعيفة و يفترض ان الاذى و الاهتمام الزائد لجسم الطفل و احتياجاته الجسمية اكثر من الاحتياجات العاطفية الثعورية و عدم التوافق الذاتي يؤدي الى تشويه التعاطف الانفعالي (Taylor, 1997:2). و عليه يؤكد (تايلر) ان الالكسيثيميا ترجع الى اضطرابات في عملية التفكير الخاصة بالعواطف والمشاعر (الحدث الداخلي) نتيجة لعدم تتمية قدرات الفرد على التنكير في المواقف والاحداث وتفسيرها وتحليلها منذ الصغر في المنزل والمدرسة، وعدم تعرضه لخبرات سابقة تحثه على التعبير عن مشاعره دون خوف، ويظهر ذلك في صورة صعوبة التعبير عن المشاعر بالكلمات او من خلال نبرة الصوت وتعبيرات الوجه والجسم ، كما يرى ان عدم تدريب الطفل منذ مرحلة الطفولة المبكرة على التعبير عن مشاعره من خلال مثيرات سمعية وبصرية، بالإضافة الى عدم تدريبه على التعامل مع الاخرين وتتمية لغته اللفظية وغير اللفظية قد تؤدي الى اضطراب في الوظائف الوجدانية والمعرفية واللغوية للطفل، ومن ثم صعوبة فهم مشاعره ومشاعر 
الاخرين والتعبير عنها في صورة لفظية وغير لفظية، كما أن محدودية الأنا فيما يخص القدرات الترميزية وعدم القدرة على ترميز الصراع، وبالتالي تحدث حلقة مفرغة تؤدي الى انقطاع نفسي مباشر، اذ يتم اختزال الصراع في الجسد، فيظهر نوع من التنكير العملي الذي يقطع العلاقة مع أي تمثيل نفسي بدون عواطف ( Taylor, 1997:7) . و يظهر هناك عجز في الأنا، حيث يكون تصعيد للنشاط الانفعالي الداخلي والذي من نتائجه ظهور الاجهاد الذي يتحول الى اعراض جسية، هذا النشاط يختلف عن النشاط العقلي السيكوسوماتي للأشخاص الذين يعانون من فقد العواطف راجع الى نموذج العجز الذي يظهر اعراض عقلية لا واعية، والخوف من الصراع يستوجب آلام الجسية بدلا من الالام النفسية، لذلك الفرد الذي يعاني من الاككيثيميا يبدي جدولاً عيادياً يتميز بعدم التلذذ وانكار الألم وكل العواطف المتعلقة باللذة، فهو خالٍ من المعلومات الحسية العاطفية التي من شأنها أن تحمي الفرد من الخطر الحالي الذي يهدد الأنا (Olivier,2013) (85) م يُشير (تايلر) أن مفهوم الالكسيثيميا يتكون من ثلاث عوامل او مكونات رئيسة ، هي: - - صعوبة تحديد المشاعر (Difficulty Identifying feeling) : الصعوبة في قدرة الفرد على تحديد المشاعر والتميز بينهما وبين الاحساسات البدنية التي تكون مصاحبة الاثارة الانفعالية. - معوبة وصف المشاعر (Difficulty Describing feeling): الصعوبة في قدرة الفرد على وصف المشاعر لفظياً للأخرين. - - التفكير الموجه نحو الخارج: (Externally Oriented Thining): القدرة على التنكير الفعال لموجه خارجياً والذي يركز على تفاصيل الاحداث الخارجية والاعراض البدنية والغياب النسبي للتحليلات الداخلية (4-3 : Taylor, 1997) اعتمد الباحث نظرية (تايلر،1997) كأطار نظري للبحث الحالي وذلك لا عتماده المقياس الذي تم بناءه في ضوء هذه النظرية فضلاً عن التعريف النظري الذي اعتمد في بناءه : المحور الثاني. التدين : ب

يعد التدين نمط سلوكي وأسلوب حياة بغرض التمسك والالتزام بأفكار المعتقد الديني وتعاليمه تجاه الخالق والمجتمع، فالمتدين يتميز بالإرادة لتعديل السلوك استجابة لمضمون العقيدة الدينية، بصرف النظر عن نوع العقيدة التي يعتقد بها ، ذلك ان الإنسان عبر التاريخ استجاب لنداء الفطرة الدينية مما جعل الدين يسهم في نشر الحقائق والمفاهيم والمبادئ الربانية لبناء الإنسان 
وإصلاح بيئته الاجتماعية لخلق الأمن الذاتي والاجتماعي له، فالدين يسعى لمصلحة الإنسان والأصول الدينية والتي يمكن أن تكون أساسا لبناء أنموذج متميز يصلح للتطبيق في المجتمعات الإنسانية( القحطاني، وطلافحة،2007: 154). وبما أن شخصية الفرد ذات جوانب مفقودة يحتاج كل منها إلى الإشباع، فكما أن الجانب البيولوجي له مطالب ينبغي إشباعها كذلك فان الجانب الروحي له مطالب قد بينها الدين، فكلما تم توجيه الفرد إلى القيام بالأعمال الصالحة، تحقق النمو الروحي له، وذلك بتقوية صلته باله (الدباغ، 1994: 66) ، وقد حدد الدين وظائف متعددة تجاه الفرد، فهو الذي يعطيه الثعور والإحساس بالأمن والطمأنينة والاستقرار، ويحدد للفرد هويته وانتمائه للجماعة، وقبوله للقيم والمعتقدات التي ينظمها الدين، حول الطبيعة البشرية، ومن خلال مشاركة الفرد في العبادات والثعائر (أبو جادو، 2000: 128). : • عرف الإنسان الله بالفطرة منذ بدأ الخليقة، واستدل الإنسان من خلال الطبيعة الرهيبة الله حيث الكواكب والنجوم والليل والنهار والظواهر الطبيعة والمخلوقات المختلفة، وقد تتدخل التتشئة لتغير هذا المسار قال رسول الله صلى الله عليه وآله وسلم " كل مولود يولد على الفطرة فأبواه يهودانه أو ينصرانه أو يمجسانه " . و تفاوت النظر لمفهوم الدين، إذ ينظر المسلمين للدين فهو الإيمان بوجود الله وأحقيته بالعبادة دون سواه، وتتفيذ الثريعة التي أرسل بها رسول الله وفي كافه جوانب الحياة، لما فيه خير الإنسان في الدنيا والآخرة. وتوسع (الصنيع، 1998) في شرح مفهوم التدين في كتابه التدين علاج الجريمة حيث يتمثل في التعرف على الله من خلال

$$
\text { المصدر الأساسي للتشريع ( القرآن الكريم) (الصنيع، 1998: 147). }
$$

لقد وجد الدين في الدنيا منذ الوقت الذي أراد الله فيه نزول سيدنا آدم - عليه السلام - إلى الأرض حيث خاطبه بقوله تعالى

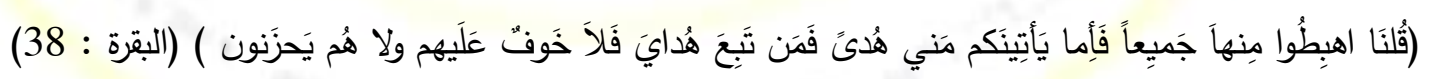
إن جميع ما في الأرض من مختلف الديانات، قد سميت بأسمائها، إما نسبة إلى اسم رجل خاص، أو أمة معينة فمثلا المسيحية أخذت اسمها من السيد المسيح- عليه السلام - والبوذية على اسم بانيها بوذا، وغير ذلك إلا الإسلام فإنه لا ينتسب إلى رجل خاص ولا إلى أمة بعينها، وإنما يدل على صفة خاصة يتضمنها معنى كلمة الإسلام، وما يظهر من هذا الاسم أنه ما 
عني بإيجاد هذا الدين وتأسيسه رجل من البشر، وليس خاصًا بأمة معينة بل هو لأهل الأرض جميعًا وغايته أن يحليهم بصفة الإسلام، فكل من اتصف بهذه الصفة من غابر الناس فهو مسلم، فلذا سمي الدين بالإسلام ( المودودي، 1982: 83). ووفقاً للمنظور الاسلامي فأن عبادة الله عز وجل لا تقتصر على مجرد الفرائض من صوم وصلاة وغيرها، اذ من السهل ان يمارس الانسان التدين الظاهري ويستعرضه أمام الناس حتى يقال إنه انسان تقي وورع ، ان المرائي هو الذي يستعرض التدين كمثل يتقن ويبدع في أداء دوره ليقنع المشاهد بأن ما يراه حقيقة ، اذ ليس ما يقوم به الممثل على خشبة المسرح هو دوره الفعلي في الحياة ، وبالمثل فإن من يستعرضون ديانتهم أمام أكبر عدد من المشاهدين ، لا لشيء الا لكي يمجدوا من الناس ويمتدحه البشر بغية للضفر بمكانة اجتماعية او سياسية تمكنهم من الوصول لمبتغاهم الحقيقي ولكن الله يميز اتجاهات القلب ونياته ، فتجد الثخص الظاهري التوجه الديني يتكلم عن الدين على المستوى المعرفي (تدين معرفي ) ، ولكن العواطف والسلوكيات ضعيفة فهو ببساطة لم يصل للتدين على المستوى السلوكي او الوجداني . اما جوهري التدين فتجده اقل اهتماماً بمظاهر الدين واكثر تمسكاً بمبادئه الحقيقية. (غرب، 2009: 323-342). • جوانب التدين في الإسلام:

إن القارئ للقرآن الكريم والسنة المطهرة والكتب الإسلامية يجد أن هنالك جوانب وأبعادًا للتدين وإن اختلفت في مسمياتها بسبب طبيعة التدين وإنها تطبيق وترجمة لتعاليم الدين، إلا أن مضمونها واحد. فقد ذكر (عسيري، 1991: 176) أن جوانب التدين في الإسلام تختلف عن جوانب التدين في الأديان الأخرى، وأنه لا يمكن حصرها، وقد ذكر أبرز تلك الجوانب وهي: - عبادة الله سبحانه وتعالى وتتضمن إقامة دعائم الدين من صلاة وزكاة وصوم وحج، تقوي رابطة الفرد بربه من خلال الذكر والدعاء والخشية والثكر والصبر والصدق والحياء. - - معاملات الفرد مع الآخرين من خلال الأمر بالمعروف والنهي عن المنكر والتواد والمروءة والتعاون والعدل والعفو

$$
\text { والرحمة ولين الجانب والتواضع وبر الوالدين وغيرها. }
$$

من خلال عرض ما عرض عن التدين يعد التشريع الاسلامي اكثر تميزاً من غيره من التشريعات بوصفه تشريعاً ربانياً شملاً وواضحاً وواقعياً ضمن للفرد الكثير من الحقوق المقرة له ، اذ ان الدين الاسلامي دين متكامل ووحدة متماسكة من الأبعاد 
الرئيسية من عقائد، وعبادات، ومعاملات وأخلاق، فالعبادات ليست طقوسًا مبهمة، ولاهي تكليف بأعمال لا معنى لها، بل هي تدريبات يومية لتعويد الفرد أن يحيا بأخلاق صحيحة يتمسك بها، كما هي نتيجة لمعتقدات راسخة، وتدفع الفرد في معاملات سوية مع أفراد مجتمعه، متوجهًا في كل ذلك ابتغاء رضاء الله. كما ان الالتزام الديني والتدين يعكس لنا شعوراً عاماً بالامن والطمأنينة والتوافق النفسي والاجتماعي لذلك فأن التدين يعد من الجوانب الهامة التي تستدعي البحث والدراسة ،كونه ذا مكانة في بناء النفس والمجتمع ، بأعتباره تنظيماً نفسياً ثابتاً من العمليات المعرفية والوجدانية والسلوكية الموجهة للثخص فكرياً وعقائدياً

$$
\text { واخلاقياً . }
$$

دراسات سابقة

اولاً. دراسات سابقة تتاولت الآكسيثيميا :

• دراسة البنا (2003)

(العلاقة بين الآكسيثيميا وانماط التعامل مع الضغوظ )

هدفت الدراسة الى الكثف عن العلاقة بين الآكسيثيميا وانماط التعامل مع الضغوط ولتحقيق ذلك تم تطبق مقياس تورنتو

للالكسيثيميا ومقياس عمليات تحمل الضغوط على عينة مكونة من (290) طالب وطالبة من طلاب الجامعة ،157 طالبا

133طالبة وأشارت النتائج فروق دالة احصائيا بين الجنسين من طلاب الجامعة في الآكسيثيميا في اتجاه الذكور، كما اشارت النتائج الى وجود فروق دالة احصائيا بين مرتفعي الدرجة ومنخفضي الدرجة على مقياس الآكسيثميا في اساليب التعامل مع

$$
\begin{aligned}
& \text { الضغوط في اتجاه مرتغعي الدرجة. (البنا، } 2003 \text { : 19-31). } \\
& \text { دراسة دهمش (2017): }
\end{aligned}
$$

(مستوى صعوبة التعرف على المشاعر ( الأكسثيميا) دراسة وصفية مقارنة بين المراهقين العدوانيين وغير العدوانيين) هدفت الدراسة إلى معرفة كل من مستوى صعوبة التعرف على المشاعر( الأكسشيما ) والسلوك العدواني لاى المراهتين، بالإضافة إلى معرفة الفروق في درجة الأكسشيميا وأبعادها بين العدوانيين وغير العدوانيين، وتم الاعتماد على المنهج الوصفي حيث بلغت عينة البحث ( 200) مراهق ومراهقة تراوحت اعمارهم ما بين ( 15-17) وطبق عليها كل من مقياس الأكسثيميا (TAS-20) الدراسة في الأخير إلى أن : n - n 
- - لدى المراهقين مستوى صعوبة التعرف على المشاعر ( الأكسشيميا ) مرتفع بنسبة (56.5\%). - - لدى المراهقين مستوى سلوك عدواني مرتفع بنسبة (45\%).

- وجود فروق في درجة الأكسشيميا وأبعادها بين المراهقين العدوانيين وغير العدوانيين عند (0.01) لصالح العدوانيين ما

$$
\begin{aligned}
& \text { عدا بعد التفكير الموجه نحو الخارج. (دهمش ، 2017: أ). } \\
& \text { ثانياً: دراسات سابقة تتاولت التدين : } \\
& \text { • دراسة الثويعر (1989): } \\
& \text { (علاقة الالتزام الديني في الإسلام بقلق الموت) }
\end{aligned}
$$

هدفت الدراسة الى الكثف عن علاقة الالتزام الديني في الإسلام وعلاقته بقلق الموت .وكانت العينة عشوائية من

العاملين في مجال التعليم بمختلف مراحله في مدنية جدة، تراوحت أعمارهم بين (25-40) سنة وكان عدد العينة (287) منهم

(142 ذكور، 145 اناث) وأما أدوات الدراسة المستخدمة فهي مقياس الالتزام الديني ومقياس قلق الموت، ومن نتائج الدراسة :

وجود علاقة سالبة دالة إحصائيًا بين مستوى الالتزام الديني في الإسلام ومستوى قلق الموت لدى عينة الذكور (الثويعر،

(1989

$$
\text { • }
$$

(العلاقة بين التفكير الإيجابي وأساليب التتشئة الأسرية ومستوى السلوك الديني والتحصيل الدراسي لاى طلاب المرحلة الثانوية

$$
\text { بالسودان) }
$$

هدفت الدراسة التعرف على العلاقة الارتباطية بين التفكير الإيجابي وأساليب التتشئة الأسرية ومستوى السلوك الديني والتحصيل الدراسي وبلغت عينة الدراسة ( 374 ) طالبًا من المرحلة الثانوية، واستخدم الباحث عددًا من المقاييس منها :مقياس التتشئة الأسرية من إعداد الباحث، مقياس تورنس للتفكير الابتكاري تقنين عبد الله النافع وآخرين ومقياس السلوك لديني من إعداد نصار، وقد توصلت الدراسة إلى نتائج أهمها: وجود علاقة ارتباطيه دالة إحصائيًا بين درجة التفكير الابتكاري ومستوى السلوك الديني، وكذلك بين التفكير الابتكاري والتحصيل الدراسي. (الصالح ، 2002: 2).

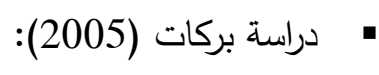

(التوجه نحو الالتزام الديني في التكيف النفسي والاجتماعي، وعلاقته ببعض المتغيرات) 
هدفت الدراسة الى التعرف على تأثير التوجه نحو الالتزام الديني في التكيف النفسي والاجتماعي، وعلاقته ببعض المتغيرات المرتبطة بالطالب الجامعي، الجنس، العمر، التخص، التحصيل الأكاديمي، وعمل الأب والأم، وقد استخدم الباحث مقياس التوجه نحو الالتزام الديني، ومقياس التكيف النفسي والاجتماعي لطلبة الجامعة، واشتملت عينة الدراسة على (200) طالب وطالبة وأظهرت نتائج الدراسة وجود تأثير جوهري لتوجه الطلاب نحو الالتزام الديني في مستوى تكيفهم النفسي والاجتماعي لمصلحة الطلبة ذوي التوجه المرتفع، ووجود تأثير لمتغيرات الجنس، التخصص، والعمر في التوجه نحو الالتزام الديني، وذلك لمصلحة الإناث والطلاب ذوي التخصصات التربوية (بركات ، 2005: 61). منهجية البحث وإجراءاته: : Method of the Research أولاً : منهجية البحث يعد المنهج الوصفي من المناهج الأكثر شيوعا في التفسير العلمي المنظم لوصف ظاهرة أو مشكلة محدة وتصويرها كميا عن طريق جمع البيانات والمعلومات المقننة عن الظاهرة واخضاعها للدراسة (قاسم ، 1999: 60). لذا اعتمد الباحث المنهج الوصفي الارتباطي في الدراسة الحالية . ثانياً : مجتمع البحث Population of the Research: يتكون مجتمع البحث الحالي من طلبة جامعتي (القادسية والكوفة) الصف الرابع فقط للدراسة الصباحية للعام الدراسي (2019-2020) من التخصصين العلمي والإنساني وكان عددهم (9089) طالباً وطالبة موزعين وفقاً لمتغير التخصص بواقع (3823) طالباً وطالبة من التخصصات الإنساني نسبتهم (42\%) من المجتمع الدراسة و(5255) طالباً وطالبة من التخصصات العلية ونسبتهم (58\%)، وموزعين ايضاً وفقاً لمتغير الجنس بواقع (3817) من الذكور وكانت نسبتهم (42\%) و • (5272) من الاناث نسبتهن (58) ثالثاً : عينة البحث Sample of the Research: تمّ اختيار عينة بلغت (400) طالباً وطالبة من مجتمع طلبة جامعتي القادسية والكوفة وبنسبة (4.5\%) تقريباً، موزعين على وفق النوع بواقع (168) طالباً و(232) طالبة، أما ما يتعلق بالتخصص فقد بلغ عدد الطلبة في التخصص العلمي (232) طالباً وطالبة، على حين بلغ عدد الطلبة في التخصص الإنساني(168) طالباً وطالبة.، وكما موضح في جدول (1) الذي يعرض تفاصيل عينة البحث موزعة حسب التخصص والنوع. 
جدول (1)

أفراد عينة البحث موزعين حسب النوع الاجتماعي والتخصص الدراسي

\begin{tabular}{|c|c|c|c|c|c|}
\hline \multicolumn{3}{|c|}{ عدد الطلبة للمرحلة الرابعة } & \multirow{2}{*}{ اسم الكلية } & \multirow{2}{*}{ نوع التخصص } & جامعة \\
\hline المجموع & أ & ذ & & & \multirow[t]{3}{*}{ القادسية } \\
\hline 130 & 75 & 55 & \multicolumn{2}{|c|}{ 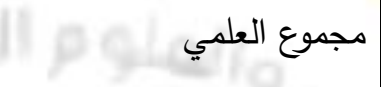 } & \\
\hline 72 & 42 & 30 & \multicolumn{2}{|c|}{ مجموع الانساني } & \\
\hline 102 & 59 & 43 & & مجموع العلمي & \multirow{2}{*}{ جامعامة } \\
\hline 96 & 56 & 40 & r & مجموع الانساني & \\
\hline 400 & 232 & 168 & \multicolumn{3}{|c|}{ مجموع العينة الكلي } \\
\hline
\end{tabular}

كابعاً: اداتا البحث Scales Of The Research: اولاً: مقياس الالكسيثيميا

لأجل اعتماد أداة لقياس الاككيثيميا لاى طلبة الجامعة اطلع الباحث على الأدبيات والدراسات السابقة التي تناولت موضوع

Bagby ) لباجبي وزملائه (Toronto Alexithymia Scale: TAS-20) الاكسيثيميا ومنها مقياس تورنتو للالكسيثيميا و وهو الكقياس الذي اعتمده الباحث وعمل على تكييفه في بحثه الحالي . parker \& Taylor, 1994 وصف المقياس

يحتوي هذا المقياس على (20) فقرة في ثلاث مجالات : المجال الاول (صعوبة تحديد المشاعر) يتكون من ( 7) فقرات والمجال الثاني (صعوبة وصف المشاعر) يتكون من (5) فقرات والمجال الثالث (التوجه الخارجي في التفكير) يتكون من (8) فقرات فيضع المستجيب أشارة ( ل) أمام البديل الذي ينطبق عليه في الفقرة التي يفضلها وقد اعتمد الباحث أسلوب ليكرت في وضع بائل الإجابة لفقرات مقياس الالكسيثيميا. صلاحية الفقرات (الصدق الظاهري للمقياس): 
لأجل التحقق من صلاحية فقرات مقياس الالكسيثيميا وبدائل الاستجابة تم عرض الفقرات والبدائل على مجموعة من الخبراء المتخصصين في التربية وعلم النفس بلغ عددهم (10) خبيراً الملحق ()،وفي ضوء الملاحظات التي أبداها الخبراء، لم يتم تعديل الفقرات وتم اعتماد قيمة النسبة المئوية المحسوبة معياراً لبقاء الفقرة من عدمها إذا كانت اذ كانت جميع الفقرات مقبولة بنسبة 100 \%

$$
\begin{aligned}
& \text { - - التحليل الإحصائي لفقرات مقياس الالكسيثيميا: } \\
& \text { أ - حساب القوة التميزية لفقرات المقياس }
\end{aligned}
$$

ويقصد بالقوة التمييزية للفقرات مدى قدرة فقرات المقياس على التمييز بين ذوي المستويات العليا وذوي المستويات الدنيا

(Ghisell et.al.,1981) من الإفراد بالنسبة للسمة التي تقيسها الفقرة ويشير جيزل وآخرون

ومن اجل حساب القوة التمييزية لفقرات مقياس الالكسيثيميا اعتمد الباحث أسلوب المجموعتين المتطرفتين وكالاتي:

$$
\text { - - أسلوب المجموعتين المتطرفتين : - 20 - }
$$

لتحقيق ذلك قام الباحث بتطبيق المقياس على عينة البحث البالغ عددها(400) طالب وطالبة ، بعد ذلك اختيرت نسبة (27\%) من الاستمارات الحاصلة على أعلى الدرجات وسميت بالمجموعة العليا، وكذلك نسبة (27\%) من الاستمارات الحاصلة على أدنى الدرجات ،وسميت بالمجموعة الدنيا، تم حساب الوسط الحسابي والانحراف المعياري للمجمعة العليا و المجموعة الدنيا على فقرات المقياس البالغ عددها (20) فقرة، وتم تطبيق الاختبار التائي لعينتين مستقلتين ، وعُدّت القيمة التائية المحسوبة مؤشراً لتمييز كل فقرة عن طريق مقارنتها بالقيمة التائية الجدولية والتي تساوي(96،1،) عند مستوى دلالة(05) وبدرجة حرية (214) وقد تبين أن جميع الفقرات مميزة ودالة إحصائياً اذ تراوحت القيمة المحسوبة للفقرات بين (2,853 - 14,602) ب. علاقة درجة الفقرة بالدرجة الكلية للمقياس: لتحقيق ذلك فقد استعمل الباحث معامل ارتباط بيرسون لاستخراج معامل الارتباط بين درجات كل فقرة والدرجة الكلية لمقياس الالكسيثيميا، وتبين أن جميع معاملات الارتباط دالة إحصائياً عند مقارنتها بالقيمة الحرجة لمعامل الارتباط البالغة (0,098)عند مستوى دلالة (0,05) ودرجة حرية (398) اذ تراوحت قيم معامل الارتباط بين (0,146 - 0,522) الخصائص القياسية (السايكومترية) للمقياس: تحقق الباحث من الخصائص السايكومترية لمقياس الالكسيثيميا على النحو الآتي: 
قد تحقق الباحث من نوعين للصدق هما الصدق الظاهري وصدق البناء وعلى النحو الآتي :

1

إذ تحقق هذا النوع من الصدق بعد أن عرض الباحث فقرات مقياس الالكسيثيميا وبدائله على مجموعة من المتخصصين في مجال علم النفس والإرشاد النفسي والقياس والتقويم بلغ عددهم (10) محكماً، للحكم على مدى صلاحية الفقرات الموضوعة ضمن مجالات المقياس، وقد تمت الموافقة على جميع فقرات المقياس من قبل السادة المحكمين، بحيث أصبح المقياس صالح من الناحية المنطقية. 2

قام الباحث بالتأكد من هذا النوع من الصدق من خلال التحليل الإحصائي لفقراته وعلى النحو الآتي: (علاقة درجة الفقرة بالدرجة الكلية للمقياس ، والقوة التمييزية للفقرات ). ثانياً: ثبات المقياس Scale Reliability. لغرض إيجاد ثبات مقياس الالكسيثيميا فقد أعتمد الباحث على طريقتين هما:

أولاً : طريقة إعادة الاختبار Test-Retest Method

لغرض استخراج الثبات بهذه الطريقة فقد قام الباحث بتطبيق المقياس على عينة الثبات التي تكونت من (60) طالب وطالبة تم اختيارهم بطريقة عشوائية، وبعد مرور مدة أسبوعين من التطبيق الأول أعيد تطبيق المقياس مرة ثانية على المجموعة نفسها، ثم صححت إجاباتهم، وباستعمال معامل ارتباط بيرسون بين درجات التطبيقين ، بلغ معامل الثبات (0,85) وتعد هذه القيمة مؤشراً جيداً على مدى استقرار إجابات المستجيبين على المقياس عبر الزمن. Cronbach Alpha Coefficient ثانياً : معادلة ألفا كرونباخ للاتساق الداخلي لاستخراج الثبات بهذه الطريقة تم سحب عينة عشوائية من استجابات عينة التحليل الاحصائي بلغت (100) استجابة،

$$
\begin{aligned}
& \text { وبعد تطبيق المعادلة بلغ معامل الثبات (0,82). } \\
& \text { وصف مقياس بصيغته النهائية : }
\end{aligned}
$$


يتكون مقياس الالكسيثيميا بصورته النهائية من (20) فقرة ، موزعة على ثلاثة مجالات بواقع (7) فقرات لمجال صعوبة تحديد المشاعر ، و(5) فقرات لمجال صعوبة وصف المشاعر ، و(8) فقرات لمجال التفكير الموجه خارجياً ، يختار في ضوئها المفحوص من خمسة بدائل متدرجة ، تتراوح من (1) الى (5) وفق للبديل الذي يقترب أو يبتعد عن قياس الاككسيثيميا ، لذا فإنَّ أعلى درجة يمكن أنَّ يحصل عليها المجيب في المقياس تكون (100) درجة وأدنى درجة (20) في حين يبلغ الوسط الفرضي للمقياس (60) والملحق ( ) يتضمن المقياس بصيغته النهائية. ثانياً : مقياس التدين: بعد أن حدد الباحث مفهوم التدين وفقاً للمنظور الاسلامي والاطلاع على الادبيات والدراسات السابقة التي تتاولت التدين مثل دراسة (الصنيع، 2000) ودراسة (القحطاني، 2007) ودراسة (مرزوق، 2015) وغيرها من الدراسات ، عرف الباحث التدين بأنه (سلوك يمارسه الفرد عن قناعة ، ناجم عن التزامه بعقيدة الايمان الصحيح وفعل ما امره الله به والابتعاد عن اتيان ما نهى عنه) وفي ضوء التعريف حددت الجوانب السلوكية لهذا المفهوم بالأستتاد الى الاطار النظري للبحث الحالي وفق المنظور الاسلامي وهي(اركان الايمان ، اركان الاسلام، الواجبات، المنهيات). وصف المقياس اعد الباحث المقياس بصيغة أولية مؤلفاً من (26) فقرة ، وصيغت الفقرات على شكل عبارات تقريرية ، لكل موقف خمسة بدائل هي (أوافق تماماً، أوافق بدرجة كبيرة ، أوافق بدرجة متوسطة ، أوافق بدرجة قليلة، لا أوافق ابدا). ، ويعطي البديل الأول الدرجة (5) والبديل الثاني الدرجة (4) والبديل الثالث الدرجة (3) والبديل الرابع الدرجة (2) والبديل الخامس الدرجة (1) • صلاحية الفقرات (الصدق الظاهري للفقرات): لأجل التحقق من صلاحية فقرات مقياس التدين وبدائل الاستجابة تم عرض الفقرات والبدائل على مجموعة من الخبراء المتخصصين في التربية وعلم النفس بلغ عددهم (10) خبيراً الملحق ()، للحكم على مدى صلاحية الفقرات وبدائل الاستجابة ومدى ملائمتها وإجراء ما يرونه مناسباً من تعديلات وحذف وإضافة على فقرات المقياس . وفي ضوء الملاحظات التي أبداها الخبراء، تم اعتماد قيمة النسبة المئوية المحسوبة معياراً لبقاء الفقرة من عدمها اذ كانت جميع الفقرات مقبولة بنسبة 100 \% - - - التحليل الإحصائي لفقرات مقياس التدين 
يتضمن التحليل الإحصائي لفقرات المقياس الإجراءات الآتية:

$$
\text { أ- حساب القوة التمييزية لفترات المقياس: }
$$

اتبع الباحث أسلوب المجموعتين المتطرفتين لحساب القوة التمييزية لفقرات المقياس واعتمد نسبة (27\%) للمجموعة العليا ونفس النسبة للمجموعة الدنيا.

بعد حساب الوسط الحسابي والانحراف المعياري للمجموعة العليا و المجموعة الدنيا على فقرات المقياس البالغ عددها (21) فقرة، وتم تطبيق الاختبار التائي لعينتين مستقلتين لاختبار دلالة الفروق بين درجات كل من المجموعتين، وعُدّت القيمة التائية المحسوبة مؤشراً لتمييز كل فقرة عن طريق مقارنتها بالقيمة الجدولية التي تساوي(96،1، عند مستوى دلالة(05،0) وبدرجة حرية (214) وقد تبين أن جميع الفقرات مميزة بدلالة إحصائية اذ تراوحت القيمة التائية المحسوبة بين (3,164 - 8,221) ب. علاقة درجة الفقرة بالدرجة الكلية للمقياس: استعمل الباحث معامل ارتباط بيرسون لحساب العلاقة الارتباطية بين درجات أفراد العينة على كل فقرة من فقرات المقياس والدرجة الكلية، وبعد حساب الدلالة المعنوية لكل فقرة، تبين أن جميع الفقرات ذات دلالة إحصائية عند مقارنتها بالقيمة الحرجة البالغة(0,098) عند مستوى دلالة (0,05) ودرجة حرية (398) اذ تراوحت معاملات الارتباط بين (0,220 - 0,371) وهذا يعتبر مؤشر على أن المقياس صادقاً لقياس الظاهرة التي وضع لقياسها. - - الخصائص القياسية (السايكومترية) للمقياس:

$$
\begin{array}{r}
\text { أولاً : صدق المقياس Scale Validity } \\
\text { الصدق الظاهري } 1 \text { استخرج صدق المقياس بطريقتين هما: }
\end{array}
$$

تحقق الصدق الظاهري لمقياس التذين من خلال عرضه على مجموعة من المحكمين، والآخذ بآرائهم حول مدى صلاحية فقرات المقياس وتعليماته، وقد تمت الموافقة على جميع فقرات المقياس من قبل السادة المحكمين. 2 
تم التحقق من هذا النوع من الصدق من خلال التحليل الاحصائي للمقياس وايجاد القوة التمييزية وعلاقة درجة الفقرة بالدرجة الكلية للمقياس أي من خلال الاتساق الداخلي للمقياس، وقد تبين أن جميع الفقرات مميزة ومرتبطة بالدرجة الكلية للمقياس وبدلالة إحصائية.

ثانياً: ثبات المقياس Scale Reliability.

لاإيجاد ثبات مقياس التدين فقد أعتمد الباحث على طريقتين هما: أولاً : طريقة إعادة الاختبار Test-Retest Method ولغرض استخراج ثبات المقياس بهذه الطريقة فقد قام الباحث بتطبيق المقياس على عينة الثبات التي تكونت من (60) طالب وطالبة تم اختيارهم بطريقة عشوائية، وبعد مرور مدة أسبوعين من التطبيق الأول أعيد تطبيق المقياس مرة ثانية على المجموعة نفسها، ثم صححت إجاباتهم، وباستعمال معامل ارتباط بيرسون بين درجات التطبيقين ، فكان معامل الثبات (0,88) وتعد هذه القيمة مؤشراً جيداً على مدى استقرار إجابات المستجيبين على المقياس عبر الزمن . Cronbach Alpha Coefficient ثانياً : معادلة ألفا كرونباخ للاتساق الداخلي لاستخراج الثبات بهذه الطريقة تم سحب عينة عشوائية من استجابات عينة التحليل الاحصائي بلغت (100) استجابة، وبعد

$$
\begin{aligned}
& \text { تطبيق المعادلة بلغ معامل الثبات (0,85). } \\
& \text { وصف مقياس بصيغته النهائية : }
\end{aligned}
$$

يتكون مقياس التدين بصورته النهائية من (26) فقرة ، يختار في ضوئها المفحوص من خمسة بدائل متدرجة ، تتراوح من (1) الى (5) وفق للبديل الذي يقترب أو يبتعد عن قياس التدين ، لذا فإنَّ أعلى درجة يمكن أنَّ يحصل عليها المجيب في المقياس تكون (130) درجة وأدنى درجة (26) في حين يبلغ الوسط الفرضي للمقياس (78) اذ تثير الدرجة المرتفعة الى مستوى عالي من التدين والدرجة المنخفضة الى مستوى منخفض من التدين والملحق ( ) يتضمن المقياس بصيغته النهائية.

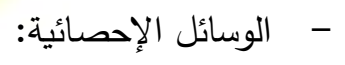

استخدم الباحث الوسائل الإحصائية المناسبة في البحث الحالي، وبالاستعانة في الحقيبة الإحصائية للعلوم الاجتماعية لمعالجات البيانات سواء في إجراءات التحقق من الخصائص السيكومترية لأدوات البحث، أو في استخراج النتائج: (SPSS) 
1- الاختبار التائي (t-test) لعينتين مستقلتين: استخدم لاختبار دلالة الفرق بين المجموعتين المتطرفتين في حساب القوة التمييزية لمقاييس البحث . 2- الاختبار التائي (t-test) لعينة واحدة: استخدم لاختبار دلالة الفرق بين المتوسط الحسابي والمتوسط الفرضي لمقاييس البحث. 3- معامل ارتباط بيرسون (Person Correlation) وقد استعمال في إيجاد الآتي: أ. علاقة درجة الفقرة بالدرجة الكلية للمقياس.

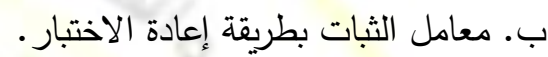
ج. إيجاد العلاقة الارتباطية بين المتغيرات. 4- معادلة الفا - كرونباخ للاتساق الداخلي، استخدمت لاستخراج الثبات بطريقة الفا للاتساق الداخلي للمقاييس. عرض النتائج وتقسيرها ومناقثتها: الهدف الاول : التعرف على مستوى الالكسيثيميا للى طلبة الجامعة . لتحقيق هذا الهدف قام الباحث بتطبيق مقياس الاككسيثيا المتكون من (20) فقرة على عينة البحث المتكونة من (400) طالب وطالبة. وأظهرت نتائج البحث إلى أن المتوسط الحسابي لدرجات هذه العينة على المقياس قد بلغ (59,887) درجة وبانحراف معياري قدره (9,394) درجة، وعند معرفة دلالة الفرق بين المتوسط الحسابي والمتوسط الفرضي الذي بلغ (60) درجة ، تبين ان الفرق غير دال احصائيا عند مستوى دلالة (0,05)، إذ بلغت القيمة التائية المحسوبة (0,240) وهي اصغر من القيمة التائية الجدولية البالغة (1,96)، وبدرجة حرية (399) وهذا يعني ان عينة البحث يمتلكون الاككسيثيميا بمستوى متوسط والجدول (2) يوضح ذلك. جدول (2)

المتوسط الحسابي والانحراف المعياري والقيمة التائية لمقياس الالكسيثيميا

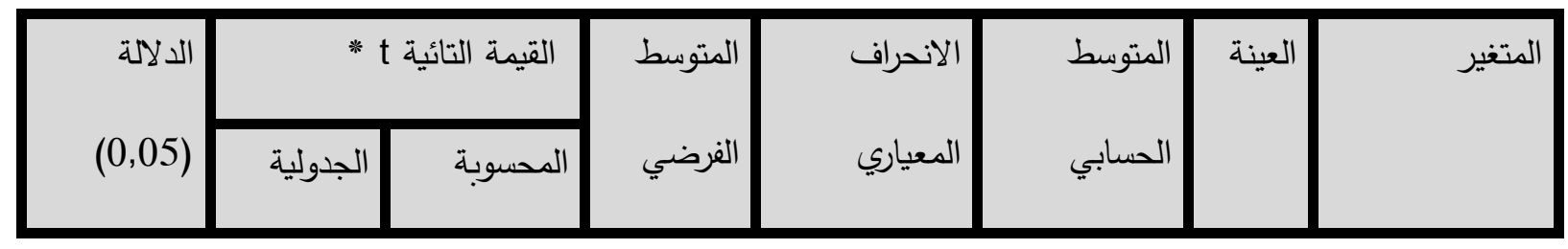




\begin{tabular}{|l|l|l|l|l|l|l|l|}
\hline غير دالة & (الكسيثيميا \\
\hline
\end{tabular}

يفسر الباحث نتيجة هذا الهدف في أن سمة الاككيثيميا يمكن التغلب عليها مع تراكم الخبرات المعرفية، والتوصل إلى طرق بديلة لأدراك المشاعر والتصرف بناء عليها مع الوقت، لان الاككسيثيا كما اورد (تايلر) ترجع الى اضطرابات في عملية التفكير الخاصة بالعواطف والمشاعر (الحدث الداخلي) نتيجة لعدم تتمية قدرات الفرد على التنكير في المواقف والاحداث وتقسيرها وتحليلها منذ الصغر في المنزل والمدرسة، وعدم تعرضه لخبرات سابقة تحثه على التعبير عن مشاعره دون خوف، (Taylor, ويظهر ذلك في صورة صعوبة التعبير عن المشاعر بالكلمات او من خلال نبرة الصوت وتعبيرات الوجه والجسم (1997:7 ـ وبما ان طلبة الجامعة هم من الراشدين ويمتلكون معارف وثقافة واسعة ساعدهم هذا في ان سمة الالكسيثيميا كانت متوسطة لديهم، وتتفق هذه الدراسة مع دراسة (البنا، 2003) التي توصلت نتائجها إلى أن مستوى الأكسيثيميا متوسطة بالنسبة للطلبة الجامعيين، وتختلف مع دراسة دهمش (2017) بسبب ان هذه الدراسة كانت عينتها من المراهقين وليس من الطلبة الجامعيين وان ظهور سمة الالكسيثيميا بصورة مرتفعة عند المراهين تفر بسبب نقص الخبرات والتغيرات النمائية عند المراهق واضطرابات النمو تؤدي الى زيادة الالكسيثيميا. الهدف الثاني : التعرف على مستوى التدين لدى طلبة الجامعة . لتحقيق هذا الهدف قام الباحث بتطبيق مقياس التدين المتكون من (26) فقرة على عينة البحث المتكونة من (400) طالب وطالبة. وأظهرت نتائج البحث إلى أن المتوسط الحسابي لدرجات هذه العينة على المقياس قد بلغ $(94,107)$ درجة وبانحراف معياري قدره (7,479) درجة، وعند معرفة دلالة الفرق بين المتوسط الحسابي والمتوسط الفرضي الذي بلغ (78) درجة ، تبين ان الفرق دال احصائيا عند مستوى دلالة (0,05)، إذ بلغت القيمة التائية المحسوبة (43,074) وهي اكبر من القيمة التائية الجدولية البالغة (1,96)، وبدرجة حرية (399) وهذا يعني ان عينة البحث يمتلكون التدين بمستوى عالي والجدول (3) يوضح

المتوسط الحسابي والانحراف المعياري والقيمة التائية لمقياس التدين

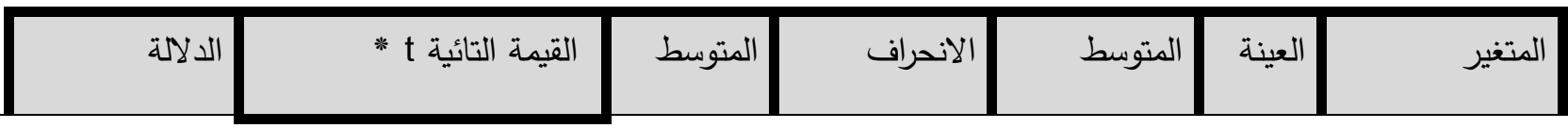


مجلة لارك للفلسفة واللسداذيات و العلوم الاجتماعية المجلد (3) العدد (42) السذة (2021) بحوث علم الاجتماع

\begin{tabular}{|c|c|c|c|c|c|c|c|}
\hline$(0,05)$ & |الجدولية & المحسوبة & الفرضي & المعياري & الحسابي & & \\
\hline دالة & 1,96 & 43,074 & 78 & 7,479 & 94,107 & 400 & التدين \\
\hline
\end{tabular}

يتضح من النتائج ان العينة يرتفع لديها التدين ويمكن للباحث تفسير هذه النتيجة في أن طبيعة المجتمع العراقي متدين ومحافظ على قيمه ومبادئه ومدافعًا عنها، فالتدين سلوك عام يمارسه كل الأفراد بمستوياته المتعددة .ولعل للمكان تأثير في التدين اذ ان ارض العراق ارض الائمة والصالحين وان المجتمع له دور من حيث انه مجتمع اسلامي محافظ على القيم والتقاليد الاسلامية وهذه الدراسة تتفق مع معظم الدراسات السابقة مثل دراسة الثويعر (1989) ودراسة المحيش (1998) ودراسة الصالح (2002) ودراسة بركات (2005) ودراسة القحطاني (2007) ودراسة كتلو (2015) ودراسة فيصل (2015) ودراسة الاحمد (2019). الهدف الثالث : التعرف على العلاقة الارتباطية بين الآكسيثيميا والتدين لدى طلبة الجامعة . لاستخراج نتيجة هذا الهدف لا بد من التأكد من الفرضية الصفرية التي تتص على انه (لا توجد علاقة ارتباطية دالة إحصائياً عند مستوى (0.05) بين الالكسيثيميا و التدين لدى طلبة الجامعة) . للتحقق من هذه الفرضية، قام الباحث بأخذ اجابات عينة البحث على مقاييس الالكسيثيميا والتدين ، ثم استعمل الباحث معامل ارتباط بيرسون فكانت النتائج كما مبينة في الجدول(4).

جدول (4) معامل الارتباط والقيمة التائية بين الالكسيثيميا والتدين

\begin{tabular}{|c|c|c|c|c|c|c|}
\hline مستوى الدلالة & \multicolumn{2}{|c|}{ القيمة التائية } & قيمة معامل & العدد & المتغير & المتغير المستقل \\
\hline$(0.05)$ & الجدولية & المحسوبة & الارتباط & & التابع & \\
\hline دالة & 1,96 & 13,878 & $-0,569$ & 400 & التدين & الالكسيثيميا \\
\hline
\end{tabular}

$$
\text { يتبين من الجدول اعلاه الاتي: }
$$

1. ان قيمة معامل الارتباط بين الالكسيثيميا والتدين بلغت (0,569-) وهي علاقة عكسية ولمعرفة دلالة العلاقة استخدم الباحث الاختبار التائي لدلالة معامل الارتباط وقد بلغت القيمة التائية المحسوبة (13,878) وهي اكبر من القيمة الجدولية 
البالغة (1,96) عند مستوى دلالة (0,05) ودرجة حرية (398)، وهذا يعني ان العلاقة بين الالكسيثيميا والتدين هي علاقة عكسية دالة احصائيا، وهذا يعني انه كلما كان مستوى الالكسيثيميا منخفضا لاى عينة البحث ارتفع مستوى التدين لديهم ومن خلال هذه النتيجة ترفض الفرضية الصفرية التي تنص على (لا توجد علاقة ارتباطية دالة إحصائياً عند مستوى (0.05) بين الالكسيثيميا و التدين لدى طلبة الجامعة) وتقبل الفرضية البديلة التي تتص على وجود علاقة، ويمكن تفسير نتيجة العلاقة العكسية بين الالكسيثيميا وعلاقتها بالتدين في ان ضعف هذا المتغير يلعب دوراً مؤثراً في زيادة مستوى التدين اذ ان الاقراد الذين لا يعانون من مشكلة التميز بين الانفعالات المختلفة مثل العاطفة والحس الجسدي، وقادرين على معرفة ماهية مشاعرهم على وجه التحديد ويستطيعون التعبير عنها بالكلمات وعلى وجه الدقة ولا تتقصهم المهارات الوجدانية الاساسية يزيد عندهم مستوى التدين، وتتفق هذه النتيجة مع الدراسات التي تتاولت التدين مثل ابو سوسو (1986) التي اظهرت نتائجها وجود علاقة موجبة بين التوافق النفسي والتدين أي ان التدين يلعب دوراً في توافق الفرد مع بيئته ، ودراسة الثويعر (1989) التي اظهرت نتائجها وجود علاقة سالبة بين التدين وقلق الموت ، ودراسة المحيش (1998) التي اظهرت نتائجها وجود علاقة موجبة بين التدين

$$
\text { التوصيات : في ضوء نتائج البحث التي تم التوصل إليها يوصي الباحث بما يأتي :- }
$$

1. الاهتمام بالأساليب والأنشطة والبرامج الإرشادية التي تحفز طلبة الجامعة على تتمية الوعي بالانفعالات والتعبير عنها وتتمية وتعزيز الجوانب الايجابية عندهم في كيفية مواجهة المواقف الاجتماعية والأكاديمية التي يواجهونها في الجامعة ليجعلهم متوافقين مع البيئة بصفة خاصة والمجتمع بصفة عامة. 2. رفد الوحدات الإرشادية في الجامعات والمرشدين التربويين والمعالجين النفسيين بمقاييس الدراسة الحالية لغرض التشخيص للجوانب السلبية التي تصدر عن الأفراد في حالات زيادة درجات الالكسيثيميا عندهم أو ضعف التدين لديهم. 3. زيادة أعداد حلقات تحفيظ القرآن الكريم ومجمعات العلم والتربية في المدن والقرى، مع الاهتمام بتطويرها لتعميق نتائجها الايجابية المميزة. 4. ضرورة العمل على زيادة الوعي فيما يتعلق بالتعبير عن المشاعر والافكار كنوع من الصحة النفسية التي تشكل جزءا مهما في صحة الجسم ككل. 
يقترح البحث الحالي القيام بما يأتي:

1. إجراء دراسة تبحث متغيرات البحث الحالي على عينات اخرى ومقارنتها مع الدراسة الحالية.

2. إجراء دراسة تعتمد على البرنامج الإرشادي في كيفية تخفيض الاككسيثيا لدى الطلبة.

3. إجراء دراسة حول متغيرات أخرى ترتبط بالأكسثيميا مثل نمط الثخصية ، والعلاقات الاجتماعية للطالب مع الاساتذة والاصدقاء وعلى عينات أخرى كطلبة المدارس . 4. اجراء دراسة مقارنة عن التدين عند عينات مختلفة.

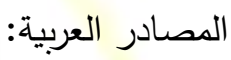

1. ابلحد فتوحي ، فاتح (1987) : مشكلات مرحلة المراهقة والثباب وعلاقها بجنس المدرس ، رسالة ماجستير (غير

منشورة ) جامعة بغداد / كلية التربية .

2. أبو جادو ، صالح محمد علي(2000) :علم النفس التربوي ، مكتبة الأنجلو المصرية، ط1 ، القاهرة. 3. بدر، أمل بنت محمد • ( 1997 ). بعض سمات الثخصية في ضوء مستوى السلوك الديني لاى عينة من طالبات جامعة الملك سعود .رسالة ماجستير غير منشورة، جامعة الملك سعود، الرياض :المملكة العربية السعودية. 4. بركات ، زياد. (2005). التوجه نحو الالتزام الديني في التكيف النفسي والاجتماعي وعلاقته ببعض المتغيرات، مجلة الثقافة النفسية المتخصصة، المجلد 16، العدد 64، ص60-67، بيروت - لبنان.

5. بني يونس، محمد . ( 2009 ) • سيكولوجية الدافعية والانفعالات، عمان :دار المسيرة للنشر والتوزيع. 6. بوعود، أسماء؛ طالب، حنان (2016) التدين وعلاقته ببعض المتغيرات النفسية الاجتماعية (التوافق الاجتماعي، تقدير الذات) عند عينة من طلبة الجامعة، مجلة العلوم الإنسانية والاجتماعية، العدد 27 ، ديسمبر 2016 ، الجزائر. 7. رش ، محمد محمد (1982) : دراسة مقارنة الثباب في الجزائر والعراق، رسالة ماجستير (غير منشورة ) جامعة بغداد /كلية التربية - ابن رشد 8. دانييل جولمان (9901) : الذكاء العاطفي ، ترجمة ليلي الجبالي ، سلسلة عالم المعرفة ، المجلس الوطني للثقافة والفنون والأداب ،الكويت . 
9. الدباغ، عفاف إبراهيم، ( 1994 ). المنظور الإسلامي لممارسة الخدمة الاجتماعية، مكتبة المؤيد للنشر والتوزيع،

الرياض، المملكة العربية السعودية.

10.دهمش عبلة . (2017). مستوى صعوبة التعرف على المشاعر( الأكسثيميا) دارسة وصفية مقارنة بين المراهقين

العدوانيين وغير العدوانيين، رسالة ماجستير ، كلية العلوم الانسانية والاجتماعية ، جامعة محمد بو ضياف المسيلة ،

الجزائر

11. الزحيلي، محمد مصطفى (2008): التدين والصحة النفسية ، ط2، دار الفضيلة ، الرياض ، ص55. 12. السويدي، وضحة، ( 1989 ) . تتمية القيم الخاصة بمادة التربية الإسلامية لاى تلميذات المرحلة الإعدادية بدولة قطر،

دار الثقافة، الدوحة، قطر •

13. الثويعر، طريفة سعود. (1989): الالتزام الديني في الإسلام وعلاقته بقلق الموت ، اطروحة دكتوراه غير منشورة، كلية

البنات ، جدة.

14. الصالح، عبد الرحمن محمد (2002). العلاقة بين التفكير الإيجابي وأساليب التتشئة الأسرية ومستوى السلوك الديني والتحصيل الدراسي لدى طلاب المرحلة الثانوية بالسودان، رسالة دكتوراه غير منشورة، جامعة الخرطوم، الخرطوم :

$$
\underline{. ~ ا ل س و د ا ن . ~}
$$

15. الصغير ، محمد بن عبدالله. (2007 ) : الثخصية والتدين موقع مدار الالكتروني.

16. الصنيع، صالح ابراهيم .( 1998 ). التدين علاج الجربمة .ط .2 الرياض :مكتبة الرشد.

17. الصنيع، صالح ابراهيم (2002 ) ، العلاقة بين مستوى التدين والقلق العام لاى عينة من طلاب جامعة الإمام محمد بن

\section{سعود الإسلامية، الرياض، مجلة جامعة الملك سعود، العلوم التربوبة والدراسات الإسلامية، العدد 14 ، 207-234.}

18. عسيري، مسفر عامر • (1991). دراسة مقارنة للفروق بين ذوي الاضطرابات النفسية العصبية والأسوياء في مستوى

التدين في الإسلام •رسالة ماجستير غير منشورة، جامعة أم القرى، مكة :المملكة العربية السعودية.

19.عمامرة، سميرة • (2018 ) التدين وعلاقته بالتوافق النفسي لدى الطالب الجامعي دراسة ميدانية بمعه العلوم الاجتماعية- والإنسانية بجامعة الثهيد حمه لخضر بالوادي، المجلة الدولية للدراسات التربوية والنفسية، العدد الأول،

مارس 2018 ، المركز الديمقراطي العربي، برلين .ألمانيا. 
20. غرب، مازن كامل. (2009) ـ التوجه الديني للمرأة العراقية وانعكاسه على مظهرها الخارجي ( محجبة -غير محجبة)،

$$
\text { مجلة البحوث التربوبة والنفسية، جامعة بغداد، العدد 3، 323- 342. }
$$

21.قاسم، محمد(1999): المدخل الى مناهج البحث العلمي، ط1، دار النهضة العربية للطباعة والنشر ، بيروت.

22. القحطاني، حسن سعيد؛ وطلافحة، فؤاد طه، ( 2007 ). التدين وعلاقته بالجمود الفكري، دراسة ميدانية على طلبة

كلية المعلمين بمدينة تبوك، مجلة مؤته للبحوث والدراسات، سلسلة العلوم الإنسانية والاجتماعية، المجلد الثالث

$$
\text { والعشرون، العدد الرابع (310- 317). }
$$

23. القعيب، سعد، ( 2003 ). التدين والتوافق الاجتماعي لطالب الجامعة، دراسة وصفية مطبقة على عينة مختارة من

$$
\text { طلاب جامعة الملك سعود، مجلة جامعة الملك سعود، م } 12 \text { ، الآداب(1 ) ، ص 33-54. }
$$

24. المودودي، أبو الأعلى. ( 1982 ). مبادئ الإسلام .ط .2 جدة :الدار السعودية للنشر والتوزيع.

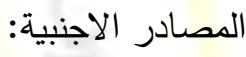

25. Agnieszka Z`ak-Goła Radosław Tomalski, Monika Ba ck-Sosnowska, Michał Ho lecki,

Piotr Kocełak ,Magdalena Olsza necka-Glinianowicz, Jerzy Chudek, Barbara Zahorska-

Mar kiewicz (2008) Al Alexithymia, depression, anxiety and binge eating in obese women.

Eur. J. Psychiat. Vol. 27, N. 3 , (149-159).

26. Dalbudak, E., Evren, C., Cetin, T., Durkaya, M., \& Cetinm R. (2010). History of trauma and relationship with alexithymia, temperament and character dimensions in male alcohol dependent inpatients. Dusunen Adam, 23(1), 1.

27. Gilbert, P., McEwan, K., Catarino, F., Baiao, R., Palmeira, L. (2014). Fears of happiness and compassion in relationship with depression, alexithymia, and attachment security in a depressed sample. Britsh Journal of Clinical Psychology, 53, $228-244$.

28. Joukamaa, M., Mattila, A. K., Poutanen, O., Koivisto, A., \& Salokangas, R. K. R. (2007). $\underline{\text { Amexithymia and life satisfaction in primary healthcare patients. }}$ 
29. Luminet, O., Vermeulen, N., Demaret, C., Taylor, G., \& Bagby, R. (2006) Alexithymia and levels of processing : Evidence for an overall degicit in remembering emotion words. Journal of Research in Personality, $40,713-733$.

30. Olivier Luminet, Nicolas Vermeulen, (2013), L’Alexithymiem Cimmentle manqué d'emotion Speut affecter notre santé, 1 ere edition de Boeck Superieur, Brucelles. BELGIQUE.

31. Sifneos, P, (1973), The prevalence of "Alexithymic" characteristics in psychosomatic patients, Psychotherapy and Psychosomatics, 22(2): 183-268,

32. Tahir, I., Ghayas, S., \& Tahir, W. (2012). Personality traits and family size as the predictors of Alexithymia among university undergraduates. Journal of Behavioral Sciences, 22(3), 104-119.

33. Taylor, G, et Bagby, R, et Parker, J, (1997), Disorders of affect regulation: Alexithymia inmedical and Psychiatric illness combridge, England: combridge University Press.

34. Taylor, G. J., \& Bagby R. M. (2000): an overview of the alexithmia construct, in ed. R. Bar-on \& J. D. A. Parker, the handbook of emotional intelligence، san Francisco: josseyvol 3, p 41-67.

35. Thomas, R,; John, H,; Earl, L, and Elisheva, D, (1992), Alexithymia as a predictor of treatment response in post - traumatic stress disorder, Journal of Traumotic Stress, 5(4): 563-573. 